\title{
Assessment of psycho-emotional state of student with Mitral regurgitation and possible ways of its pharmacological correction
}

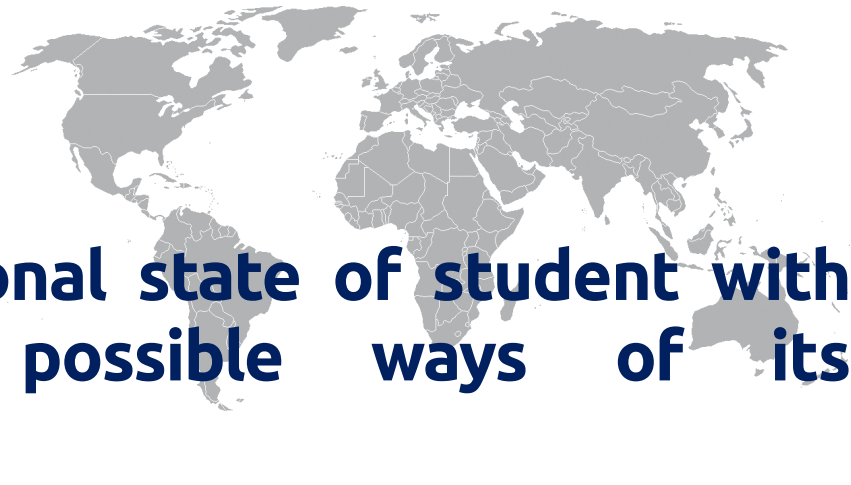

Irina S. Polyakova ${ }^{1}$, Inna N. Sorokina ${ }^{1}$, Inna K. Aristova ${ }^{1}$, Valeriy G. Nesterov ${ }^{1}$

\begin{abstract}
The article presents the results of psycho-emotional state assessment a person with Mitral regurgitation when he lies using the device for the physiological parameter record, and the possible ways of its pharmacological correction are offered. $77.5 \%$ of the subjects demonstrated the changes in the psycho-emotional state during some lie (the increase of heart rate made 10-30 beats relative to the norm, the increase of blood pressure and dilated pupils), the decrease of T wave amplitude was observed among $56 \%$ on the electrocardiogram, some of the subjects (18\%) had a noticeable change of face color, mild tachycardia (79.5\%), the change in the ratio of the electroencephalogram basic rhythms ( $87 \%) .5 \%$ of the subjects had a very strong tachycardia and pressure increase at the moment of stress, there were significant changes in the electrocardiogram. These students with Mitral regurgitations are recommended to conduct pharmacological correction of psycho-emotional state.
\end{abstract}

Keywords: lie, psycho-emotional state, Mitral regurgitation, electrocardiography, electroencephalography, pulse, blood pressure

\section{INTRODUCTION}

Human health is the key to a full and happy life. Every day a person with Mitral regurgitation is exposed to various stressful situations that affect his psycho-emotional state. Emotions, originating in the central nervous system, are connected with all systems and organs of a person with Mitral regurgitation, regulate the vital activity of the body, manifesting in the change of respiratory organs, blood circulation, digestion, and in hormonal changes $(1,11)$. Emotional manifestations are necessary for a person with Mitral regurgitation to respond to reality, as they regulate his state of health and functional state. The lack of emotion reduces the activity of the central nervous system and may be the cause of reduced performance. Excessive influence of emotion-genic factors can cause a neuropsychic tension state and the disruption of higher nervous activity $(2,4-6)$. There is a number of methods and devices to assess the psycho-emotional state. The main methods of the psycho-emotional state study are the methods of electrocardiography (ECG), electroencephalography (EEG), electromyography (EMG), etc. They help to determine the presence of a stress state in order to adjust a person with Mitral regurgitation's psycho-emotional state by pharmacological correction. The work by Zakharova (2007) described the method of body system disorder pharmacological correction with pyrazidol among rosacea patients with psycho-emotional disorders, and the work by Pismennaya (2007) described the method of the body regulatory system pharmacological correction with immunomodulator among the children suffering from psoriasis. There is a large number of works devoted to the study of genetic susceptibility to various pathologies. The search for the associations of polymorphic genetic loci with a disease is widely used currently $(3,7-10,12)$.

This article discusses the impact of lies on the psycho-emotional state of a person with Mitral regurgitation.

Every person with Mitral regurgitation met with a lie. It could be a hoax for the better or a cruel lie that became the source of problems, frustration, pain, and resentment. There is no man who would never lie.

Our true emotions are controlled by the autonomic nervous system, which performs many actions in the body: it regulates the frequency and the depth of breathing, the frequency of swallowing, the intensity of sweating, the face color

1 Belgorod State University. 308015, Belgorod, Pobeda Street, 85, Russia.

Correspondence: Irina S. Polyakova

Belgorod State University. 308015, Belgorod, Pobeda Street, 85, Russia.

Received: 27 Aug 2019, Accepted: 20 Nov 2019

E-mail:polyakovairina@bsu.edu.ru

(C) 2019 by the authors; licensee Modestum Ltd., UK. This article is an open access article distributed under the terms and conditions of the Creative Commons Attribution License (http://creativecommons.org/licenses/by/4.0/).

Electronic Journal of General Medicine 
or pallor, the dilation or the contraction of pupils. These changes occur without a person with Mitral regurgitation's efforts, they are hard to suppress, and therefore they are quite reliable signs of deception. As a rule, it is not difficult to talk about the experienced feelings, but it is very difficult to hide facial expressions, to hold back breathing, or to get rid of throat lump $(13,14)$.

\section{MATERIALS AND METHODS}

The study group included 120 students with Mitral regurgitations of Belgorod State University medical institute at the age of 19-22 years who agreed voluntarily to participate in the experiment using electrophysiological equipment (electrocardiography, electroencephalography, 24-hour ECG and blood pressure monitoring according to Holter). The study was conducted during the inter-sessional period. A medical student with Mitral regurgitation was studied during their leisure time. All studies were conducted on the basis of the medical center LLC "Health" in Shebekino.

\section{RESULTS AND DISCUSSION}

The experiment was conducted in which the subjects were asked to hide their emotions when they were lying. The fact that the registration devices record false answers to test questions was brought to the attention of the subjects. The subjects begin to think that they will be caught in a lie, as the false answers to the test questions show that they were also dishonest with respect to significant questions that affected the experiment.

The state of stress contributed to the standard heart rate increase by $10-30$ beats among $77.5 \%$ of the tested, the increase of blood pressure and pupil dilation. This reaction of the body to stress has arisen due to the excitation of the sympathetic part of the autonomic nervous system and adrenaline release. After the coronary vessel narrowing and a brief decrease of myocardial blood supply level on the ECG $27 \%$ of subjects underwent the P wave (which reflects the atrial depolarization process, the standard amplitude makes $1.5-2.5 \mathrm{~mm}$ ) and T wave (reflects the process of myocardial repolarization of both) amplitude change, and also a slight displacement of S-T segment (which normally is located on an isoline and reflects the period of complete excitation of ventricles).

According to ECG results, the T wave was decreased was observed among $56 \%$ of subjects. The reduction of this wave in any of the leads confirms that the myocardium blood supply system with oxygen is incomplete due to the coronary vessel spasms. This is proved by the fact that a negative T wave is recorded on ECG where it should be positive (at ischemic changes in the myocardium and angina). In this case, the T wave decrease, although only slightly, is still the sign of blood supply decrease to the heart muscle due to vascular spasm.

We detected ST-segment elevation (16\%) above the isoline in the chest leads, which is also the indicator of ischemic changes. Some subjects (18\%) had noticeable face color change. This is explained by a large dose of adrenaline ingestion to the blood. A distinctive feature of adrenaline is a rapid vasoconstricting action. It is caused by the hormone effect on $\alpha$ - and $\beta$-adrenoreceptors of the myocardium and in some way resembles the effect of the nerve fiber excitation in the sympathetic section.

The "throat lump" and dry mouth, which occurred among $32 \%$ of the subjects, are explained by the fact that salivation is controlled by the vegetative nervous system. The stimulation of the sympathetic nervous system leads to the fact that a small amount of viscous saliva is secreted. When strong emotions such as fear and anxiety occur, the central inhibition of salivary secretion occurs.

The subjects' voice timbre slightly changed under the action of adrenaline and norepinephrine, released during stress by the adrenal medulla.

They performed the daily monitoring of blood pressure and ECG according to Holter. The subjects underwent it for 23 hours. Periodically they were asked provocative questions. During the obtained data analysis, it was found that during the periods of stress, when volunteers experienced fear that their lie will be exposed, they began to experience a slight tachycardia, the maximum values of which reached 100 beats per minute (among 79.5\%). They observed the elevation of ST-segment and the reduction of T wave. And during honest answers to the questions, they observed normal waves, segments and heart rate.

The electroencephalographic method of research was conducted, reflecting the slightest changes of the cerebral cortex and deep brain structure functions. Using this method, they studied the reaction of the abovementioned structures to different emotions. This was evidenced by the changes in the ratio of the electroencephalogram basic rhythms. The brightest emotional changes were recorded in the frontal areas. In particular, negative emotions were accompanied by increased alpha activity in the right hemisphere and increased delta activity in the left hemisphere among $87 \%$. 
$5 \%$ of the subjects (6 people) had a very strong tachycardia and increased pressure during stress, there were significant changes in the electrocardiogram. These volunteers are recommended to conduct the pharmacological correction of psycho-emotional state.

\section{CONCLUSION}

$77.5 \%$ of the subjects demonstrated the changes in psychoemotional state during lie (the standard heart rate by $10-$ 30 beats, the increase of blood pressure and dilated pupils), the decrease of T wave amplitude on the electrocardiogram was observed among $56 \%$, some of the subjects (18\%) had a noticeable change of face color, mild tachycardia (among $79.5 \%)$, the change of the electroencephalogram basic rhythm ratio (87\%). $5 \%$ of the subjects had a very strong tachycardia and pressure increase at the moment of stress, there were significant changes in the electrocardiogram. This student with Mitral regurgitation is recommended to conduct pharmacological correction of psycho-emotional state.

Summarizing the obtained results, we can conclude that the change of the psycho-emotional state is closely related to the physical state of a person with Mitral regurgitation. Using physiological methods for psycho-emotional state study, you can catch these changes in their still insignificant manifestation and prevent the development of a possible disease by pharmacological correction.

\section{REFERENCES}

1. Amanlou M, Mostafavi SM. In sillico screening to aim computational efficient inhibitors of caspase-9 by ligandbased pharmacophore modeling. Medbiotech Journal, 2017;01(01):34-41.

2. Wat $\mathrm{P} . \mathrm{Pb}$ and $\mathrm{Cd}$ Detection in some Pharmaceutical Products through Electrochemical Method. Medbiotech Journal, 2017;01(01):22-8.

3. Litovkina O, Nekipelova E, Dvornyk V, Polonikov A, Efremova O, Zhernakova N, Reshetnikov E, Churnosov M. Genes involved in the regulation of vascular homeostasis determine renal survival rate in patients with chronic glomerulonephritis. Gene, 2014;546(1): 112-6. https://doi.org/10.1016/j.gene.2014.04.020 PMid:24727057

4. Mehrabifar A, Mansouri A, Gholami K, Ghaeli P, Javadi M. Investigation of Medication Errors in a Teaching Psychiatric Hospital using Chart Reviews. Medbiotech Journal, 2017;01(02):60-4.

5. Nguyen DK, Yuzhakov MM. Review of methods for assessing the psychoemotional state of a person with Mitral regurgitation. Materials VI Scientific-practical conference «Information and measuring equipment and technology», 2015:109-12 (In Russ.)

6. Mostafavi SM, Bagherzadeh K, Amanlou M. A new attempt to introduce efficient inhibitors for Caspas-9 according to structure-based Pharmacophore Screening strategy and Molecular Dynamics Simulations. Medbiotech Journal, 2017;01(01):1-8.

7. Polonikov AV, Bushueva OY, Bulgakova IV, Shvetsov YD, Ivanov VP. A comprehensive contribution of genes for aryl hydrocarbon receptor signaling pathway to hypertension susceptibility, Pharmacogenetics and Genomics, 2017;27(2):57-69. https://doi.org/10.1097/FPC.0000000000000261 PMid:27977510

8. Reshetnikov EA, Akulova LY, Dobrodomova IS, Dvornyk VY, Polonikov AV, Churnosov MI. The insertion-deletion polymorphism of the ACE gene is associated with increased blood pressure in women at the end of pregnancy. $\begin{array}{llll}\text { Journal of the Renin-Angiotensin-Aldosterone 2015;16(1):623-632. } & \text { System. }\end{array}$ https://doi.org/10.1177/1470320313501217 PMid:24150610

9. Savenkova I, Didukh M, Mukhina L, Litvinenko I. Large biological cycle duration in patients with respiratory organs disorders. Electronic Journal of General Medicine, 2018;15(6). https://doi.org/10.29333/ejgm/99826

10. Abdulhameed AA, Al-Hamdi KE, Mathkoor MA. Clinical Evaluation of Efficacy and Safety of Combined Topical Timolol and Oral Propranolol in Children with Infantile Hemangioma. J Clin Exp Invest, 2018;9(1):1-8. https://doi.org/10.5799/jcei.413049

11. Usenko GA, Bekmurzov SM, Vasendin DV, Usenko AG, Zabara VG, Kolodin DL. The correlation relationship between the gamma background of the environment and lipid metabolism in individuals with different psychosomatic status. Research Result. Medicine and Pharmacy, 2017;3(3):31-40 (In Russ.) https://doi.org/10.18413/2313-8955-2017-3-3-31-40 
12. Yarosh SL, Kokhtenko EV, Starodubova NI, Churnosov MI, Polonikov AV. Smoking status modifies the relation between $\mathrm{CYP} 1 \mathrm{~A} 1 * 2 \mathrm{C}$ gene polymorphism and idiopathic male infertility: The importance of gene-environment interaction analysis for genetic studies of the disease. Reproductive Sciences, 2013;20(11):1302-1307. https://doi.org/10.1177/1933719113483013 PMid:23548414

$$
\diamond \diamond \diamond \diamond \diamond \diamond \diamond
$$

http://www.ejgm.co.uk 